\title{
SÍNTESE DE ZEÓLITA 4A A PARTIR DE CAULIM PROVENIENTE DA REGIÃO DO PARAÍBA
}

\author{
K VOLLMANN $^{1}$, J. C. MOREIRA ${ }^{1}$, A. FURIGO Jr ${ }^{1}$, H. G. RIELLA ${ }^{1}$, G. S. ERZINGER ${ }^{2}$ \\ ${ }^{1}$ Universidade Federal de Santa Catarina, Departamento de Engenharia Química e Engenharia de \\ Alimentos \\ ${ }^{2}$ Universidade da Região de Joinville, Departamento de Saúde e Meio Ambiente \\ E-mail para contato: ketlynvollmann@gmail.com
}

\begin{abstract}
RESUMO - A utilização de argilas do tipo caulim como fonte de Al e Si para a síntese de zeólitas tem se mostrado economicamente vantajosa quando comparada à produção a partir de produtos químicos sintéticos. Assim, este trabalho descreve a síntese de zeólita 4A através da calcinação de caulim proveniente da região do Paraíba. Para isto foi realizada ativação térmica da caulinita a $850^{\circ} \mathrm{C}$ para a obtenção do metaculim, que foi submetido a uma reação hidrotérmica a $150^{\circ} \mathrm{C}$ por $6 \mathrm{~h}$ para a obtenção da zeólita $4 \mathrm{~A}$. As caracterizações da zeólita para a verificação da estrutura cristalográfica foram feitas utilizando as técnicas de Difrações de Raios-X e Espectroscopia de Absorção na Região do Infravermelho por Transformada de Fourier (FTIR). Os resultados obtidos comprovam que o caulim se mostra uma excelente matéria-prima para a síntese de zeólita 4A.
\end{abstract}

\section{INTRODUÇÃO}

O caulim, comumente denominado "China clay", é um dos minerais mais importantes comercialmente e um dos mais abundantes do topo da crosta terrestre (CERCENÁ, 2013). O termo caulim é utilizado tanto para denominar um tipo de argila, constituída essencialmente pelo argilomineral caulinita, de coloração branca, granulometria fina e normalmente com baixo teor de ferro, como o produto resultante do seu beneficiamento (MORAES et al., 2013; BRITO et al., 2013).

O caulim é formado por um grupo de silicatos hidratados de alumínio, principalmente caulinita e haloisita e secundariamente por diquita e nacrita, cuja composição química aproxima-se de $\mathrm{Al}_{2} \mathrm{Si}_{2} \mathrm{O}_{5}(\mathrm{OH})_{4}$, o que corresponde a cerca de 46,54\% de $\mathrm{SiO}_{2}, 39,50 \%$ de $\mathrm{Al}_{2} \mathrm{O}_{3}$ e $13,96 \%$ de $\mathrm{H}_{2} \mathrm{O}$ sob a forma de hidroxila, e outras substâncias em menor quantidade sob a forma de impurezas, tais como quartzo, micas, feldspatos, óxidos de ferro e titânio, etc. (BERTOLINO et al., 2009; BRITO et al., 2013; MORAES et al., 2013). Sua estrutura atômica consiste basicamente em uma folha de átomos de silício em coordenação tetraédrica com quatro átomos de oxigênio e uma folha de átomos de alumínio em coordenação octaédrica com dois átomos de oxigênio e quatro moléculas de água (MA et al., 2014).

As ocorrências de caulim são comuns em diversos países do mundo, porém existem poucos depósitos de boa qualidade e comercialmente exploráveis. Os mais conhecidos estão localizados em três regiões do planeta, encontrando-se eles nos estados da Geórgia e da Carolina do Sul nos Estados 


\section{9 a 22 de outubro de 2014 \\ Florianópolis/SC}

Unidos, em Cornwall no sudoeste da Inglaterra, e na região Amazônica no Brasil (HILDENBRANDO et al., 2012). No Brasil, as reservas de caulim se concentram nos estados do Pará, Amapá e Amazonas, sendo o minério já beneficiado disponibilizado para os mercados interno e externo (PINHEIRO et al., 2013). A indústria extrativa mineral no estado do Pará desempenha um papel importante na economia paraense, tanto no segmento dos minerais metálicos, minério de ferro e cobre, como a dos minerais não metálicos, como é o caso do caulim (SANTANA et al., 2012). O estado do Pará é uma das regiões mais privilegiadas do planeta em termos de exploração de recursos minerais. Muitos dos projetos de mineração em andamento no estado possuem destaque mundial por causa da qualidade do produto, mas também pela magnitude de suas jazidas e dos volumes de produção (BARATA; ANGÉLICA, 2012).

Em função de suas propriedades físicas e químicas, o caulim pode ser utilizado em uma grande variedade de produtos desde carga e cobertura para papel, pigmentos, catalisadores, matériaprima para indústria de cerâmica (BERTOLINO et al., 2009), aditivo alimentar, em pastas de dente, como material de difusão da luz em lâmpadas incandescentes e em cosméticos. Em geral, é o principal componente da porcelana (MGBEMENA et al., 2013).

Nos processos de síntese de zeólitas, a procura de matérias-primas mais econômicas resultou nos processos provenientes da utilização de argilominerais, dos quais o caulim é o mais empregado. Sendo o caulim um material que naturalmente já possui uma relação $\mathrm{SiO}_{2} / \mathrm{Al}_{2} \mathrm{O}_{3}$ próxima da requerida para síntese de zeólitas tipo $\mathrm{A}$, com propriedades adequadas ao uso ambiental, e face à existência de muitos depósitos de caulim no Brasil, é oportuno estudar o desenvolvimento de processos de síntese de zeólita a partir de caulins calcinados, visando sua aplicação na área de tecnologia ambiental (MELO; RIELLA, 2010).

A Zeólita A possui uma morfologia cúbica e geralmente é sintetizada na forma sódica. É conhecida por LTA, zeólita NaA e zeólita 4A. Quando formada a partir de caulinita, seu processo de síntese apresenta duas etapas. A primeira etapa consiste no tratamento térmico dado ao caulim, através de calcinação; na segunda etapa o metacaulim (caulim calcinado) reage com hidróxido de sódio em condições hidrotérmicas (RODRIGUES et al., 2012).

\section{MATERIAIS E MÉTODOS}

\subsection{Material utilizado}

Para a síntese de zeólita 4A foi utilizado um caulim branco proveniente da empresa Caulisa Comércio e Beneficiamento de Minérios LTDA, situada no município de Campina Grande - PB, gentilmente cedido pela empresa Colorminas.

\subsection{Síntese de zeólita 4 A}

O procedimento de síntese de zeólita 4A foi baseado nos trabalhos de Melo (2009) e Moreira (2013), com algumas adaptações. Primeiramente é realizada a ativação térmica da 
caulinita, onde o caulim é depositado em cadinhos de porcelana e calcinado em forno mufla a uma temperatura de $850{ }^{\circ} \mathrm{C}$ por 2 horas, tornando-se metacaulim. Uma amostra de $3 \mathrm{~g}$ deste metacaulim obtido foi adicionada a um reator de teflon/alumínio juntamente com $30 \mathrm{~mL}$ de solução de $\mathrm{NaOH}$ 1,25 mol/L, sob agitação para homogeneização; este sistema foi colocado em estufa, a $150{ }^{\circ} \mathrm{C}$, por um período de 4 horas à pressão autógena, para que ocorresse a reação hidrotérmica de formação de zeólita 4A. O material resultante foi lavado com água e centrifugado até $\mathrm{pH}$ próximo a 9 , e em seguida seco em estufa a $100^{\circ} \mathrm{C}$ por aproximadamente 6 horas.

\subsection{Caracterização dos materiais}

As técnicas de caracterização citadas a seguir foram empregadas para a análise das amostras de caulim, metacaulim e zeólita:

Difração de raios X (DRX): A verificação das fases cristalográficas do caulim e da zeólita foi realizada em um difratômetro difratômetro Philips (modelo X'pert), no Laboratório de Microscopia Eletrônica, do Departamento de Engenharia Mecânica da Universidade Federal de Santa Catarina (UFSC). Os ensaios foram conduzidos com irradiações variando de 5 a $25^{\circ} 2 \theta$, com intervalo de $0,05^{\circ} 2 \theta$ para cada segundo, utilizando radiação proveniente de um tubo de cobre com $\mathrm{K} \alpha$ de $1,5406 \AA$, operando a $40 \mathrm{kV}$ e $30 \mathrm{~mA}$. O tratamento de dados foi realizado utilizando o software Origin versão 8.0 como padrão para auxílio na análise quantitativa.

Espectroscopia de Infravermelho por Transformada de Fourier (FTIR): Os espectros na região do infravermelho médio para o caulim e a zeólita foram obtidos em um espectrofotômetro Shimadzu FTIR (modelo IR Prestige-21) do Laboratório de Controle de Processos (LCP) da Universidade Federal de Santa Catarina (UFSC). A amostra foi macerada juntamente com brometo de potássio $(\mathrm{KBr})$ contendo $2 \%(\mathrm{p} / \mathrm{p})$ de amostra, e depois prensada no formato de pastilha. A análise foi realizada por transmitância, com uma velocidade de $0,2 \mathrm{~cm} / \mathrm{s}$ e resolução de $4 \mathrm{~cm}^{-1}$, no intervalo de $4000-400 \mathrm{~cm}^{-1}$.

\section{RESULTADOS E DISCUSSÃO}

O difratograma de raios-X referente ao caulim e ao metacaulim é apresentado na Figura 1, demonstrando as transformações ocorridas após a ativação térmica, onde o caulim torna-se um composto amorfo. O tratamento térmico a $850{ }^{\circ} \mathrm{C}$ por 2 horas causa uma diminuição na intensidade dos picos do difratograma, indicando a perda de cristalinidade. Os picos mais altos do difratograma correspondem ao quartzo (Q) e ao argilomineral caulinita (K). 


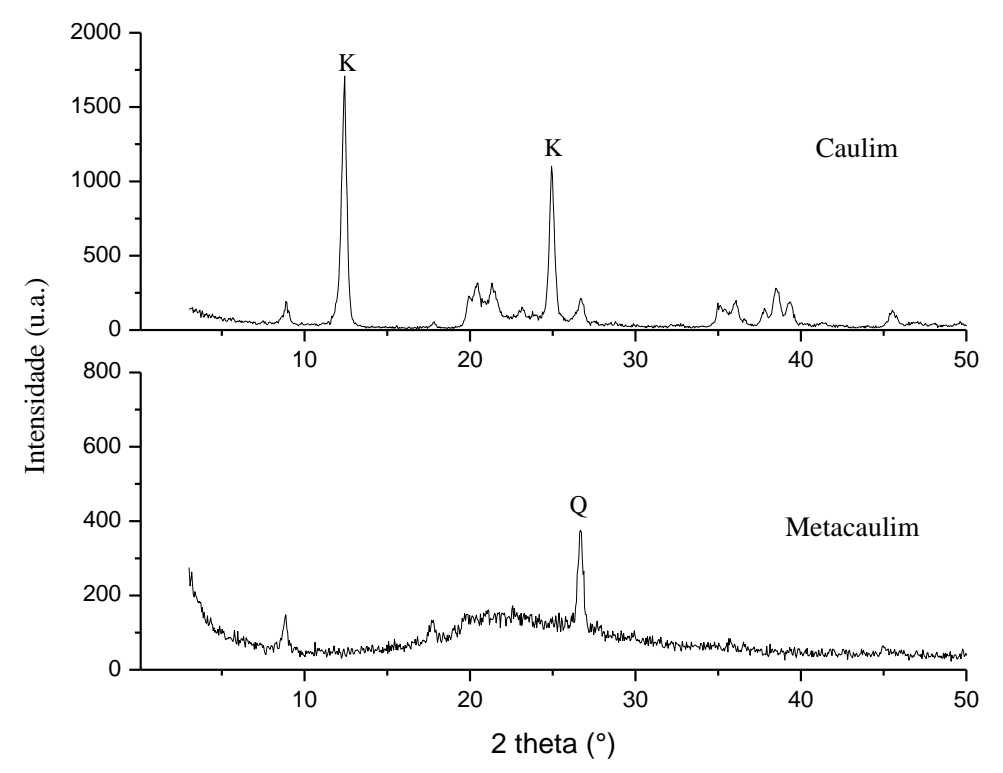

Figura 1 - DRX Caulim e metacaulim

No difratograma mostrado na Figura 2 apresenta picos estreitos e bem delineados, com elevado grau de ordem estrutural. A zeólita $\mathrm{NaA}$ sintetizada apresenta uma série de picos característicos, localizados em: $7,14^{\circ} ; 10 ; 10^{\circ} ; 12,38^{\circ} ; 16,20^{\circ} ; 21,58^{\circ} ; 23,92 ; 27,00^{\circ} ; 29,82^{\circ}$ e $34.08^{\circ}$ (RIOS et al., 2007).

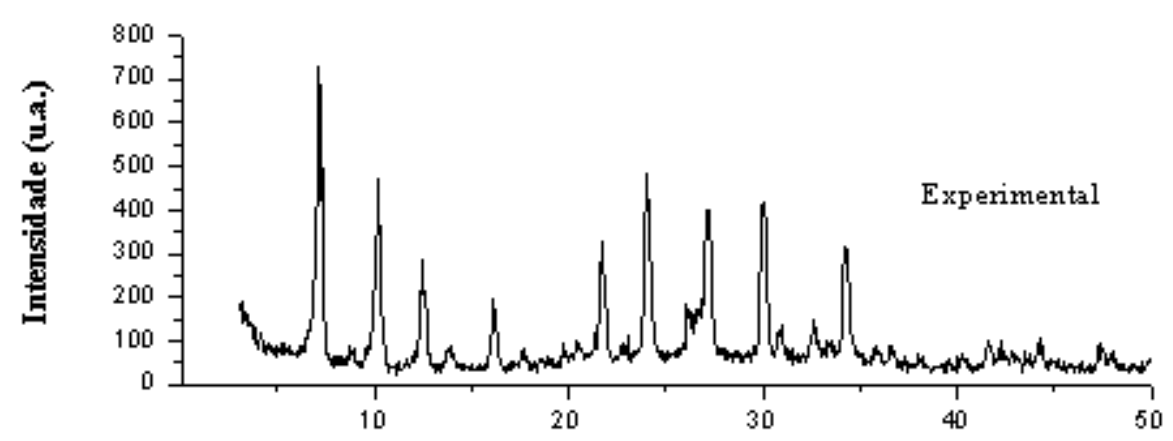

Figura 2 - DRX - Zeólita NaA experimental

Conforme mencionado por Moraes e colaboradores (2003), o quartzo é a forma mais comum de sílica, tem uma estrutura cristalina formada por retículo tridimensional de tetraedros de $\mathrm{SiO}_{4}$ ligados numa estrutura compacta. Então, a destruição da estrutura do caulim deixa o $\mathrm{Si}$ e o Al mais livres, e assim, mais adequado para a síntese de zeólitas. 
Na Figura 3 são apresentados os espectros de FTIR do caulim, metacaulim e da zeólita NaA sintetizada. As bandas de absorção observadas entre 3900 e $3500 \mathrm{~cm}^{-1}$ são as vibrações de estiramento simétrico e assimétrico da molécula de água características da caulinita, que ficam muito próximas às das hidroxilas externas; a banda em $3626 \mathrm{~cm}^{-1}$ é referente às hidroxilas octaédricas internas, que também apresentam deformações em aproximadamente 1651 e 1608 $\mathrm{cm}^{-1}$, devidas às fortes interações de $\mathrm{OH}$ na estrutura.

As bandas em 1092, 811 e $470 \mathrm{~cm}^{-1}$ representam as modificações ocorridas na transição caulim-metacaulim, após a calcinação a $850^{\circ} \mathrm{C}$ por 2 horas. As absorções que ocorrem em 1040 a1020 $\mathrm{cm}^{-1}$ correspondem às interações $\mathrm{Si}-\mathrm{O}-\mathrm{Si}$; em $800 \mathrm{~cm}^{-1}$ há as interações $\mathrm{Al}-\mathrm{O}$, e as bandas em 470 me 427 são de acoplamento O-Si-O características desta espécie de argilomineral.

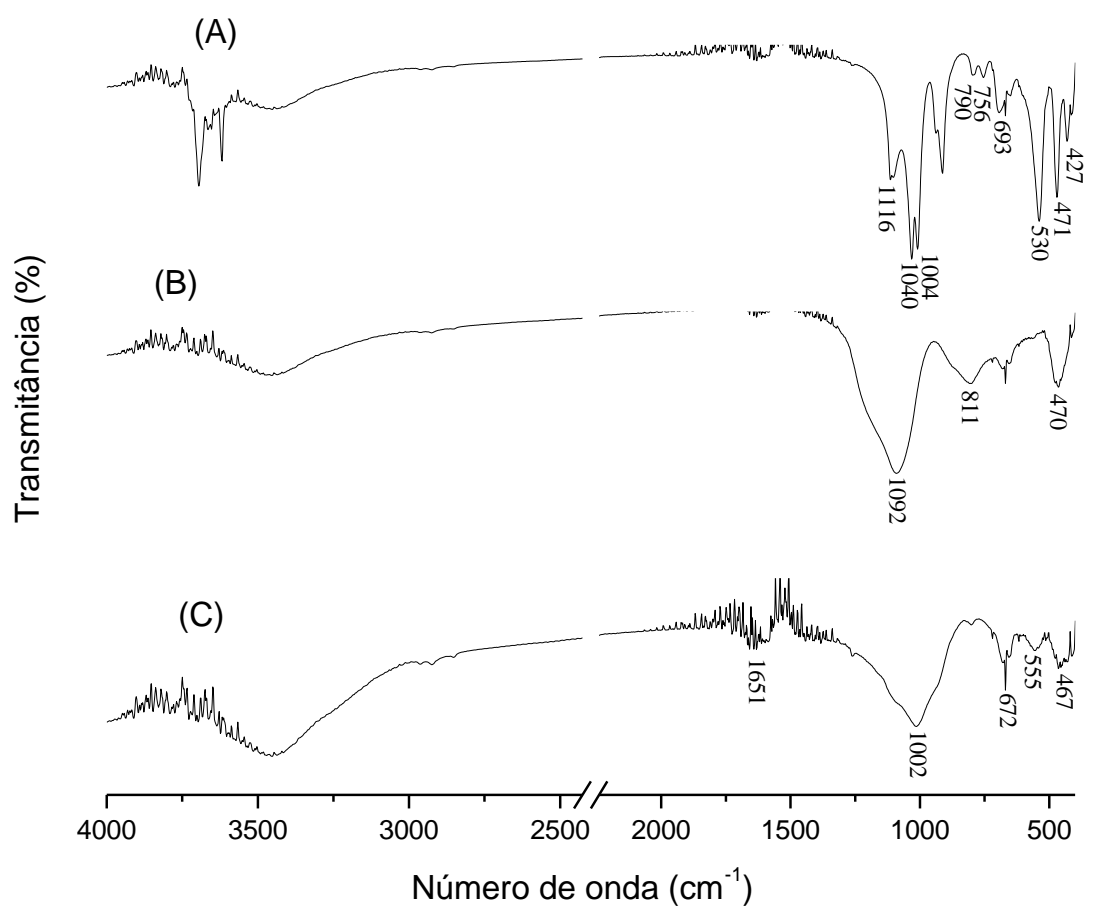

Figura 3 - FTIR - (A) Caulim, (B) metacaulim e (C) zeólita NaA

A presença de material zeolítico foi confirmada através das bandas em 1102 e $1008 \mathrm{~cm}^{-1}$, localizadas próximas a $1000 \mathrm{~cm}^{-1}$, que por sua vez é uma banda característica da ligação Si-O-Al do tetraedro $\mathrm{TO}_{4}$ de unidades primárias de construção. Entretanto, são as bandas a 672, 555 e 467 $\mathrm{cm}^{-1}$ que indicam a cristalização da zeólita A. As bandas em $680 \mathrm{~cm}^{-1}$ representam estiramentos simétricos típicos das vibrações internas primárias T-O ( $\mathrm{Si}, \mathrm{Al})$. A banda próxima a $550 \mathrm{~cm}^{-1}$ está conectada com a vibração do anel duplo de quatro tetraedros (D4R), que é dominante na unidade de construção secundária da estrutura da zeólita A. 


\section{CONCLUSÃO}

Os difratogramas de raios-X apresentados neste trabalho demonstram as transformações ocorridas com o caulim após a ativação térmica a $850{ }^{\circ} \mathrm{C}$ por um período de 2 horas. A utilização do caulim proveniente da região do Paraíba para a síntese hidrotérmica da zeólita NaA revelou ser um processo eficiente, resultando em um produto com alto grau de cristalinidade e livre de impurezas.

\section{REFERÊNCIAS BIBLIOGRÁFICAS}

BARATA, M. S.; ANGÉLICA, R. S. Caracterização dos resíduos cauliníticos das indústrias de mineração de caulim da Amazônia como matéria-prima para produção de pozolanas de alta reatividade. Cerâmica, v. 58, n. 345, p. 36-42, jan-mar. 2012.

BERTOlinO, L. C.; MENDONÇA, B. C.; OliveIRA, S. B.; LUZ, A. B.; FREIRE, F. R. Caracterização mineralógica e tecnológica do caulim de Silvânia, estado de Goiás. Anu. Inst. Geociênc., v. 32, n. 2, p. 26-32, dez. 2009.

BRITO, C. W. Q.; RODRIGUES, F. H. A.; FERNANDES, M.V. S.; SILVA, L. R. D.; RICARDO, N. M. P. S.; FEITOSA, J. P. A.; MUNIZ, E. C. Síntese e caracterização de hidrogéis compósitos a partir de copolímeros acrilamida-acrilato e caulim: efeito da constituição de diferentes caulins do nordeste brasileiro. Quím. Nova, v. 36, n. 1, p. 40-45, 2013.

CERCENÁ, R. Preparação, caracterização, propriedades mecânicas e térmicas de sistemas EPDM/caulim e EPDM/nanocaulim. 2013. Tese de doutorado. Programa de Pós-Gradação em Ciência e Engenharia de Materiais, Universidade Federal de Santa Catarina - UFSC. 208p.

FERNANDES, M. V. S.; SILVA, L. R. D. Estudo da intercalação de compostos orgânicos em caulins na forma ácida. Cerâmica, v. 57, n. 342, p. 214-224, abr-jun. 2011.

HILDENBRANDO, E. A.; ANGÉLICA, R. S.; NEVES, R. F.; VALENZUELA-DIAZ, F. R. Síntese de zeólita do tipo faujasita a partir de um rejeito de caulim. Cerâmica, v. 58, n. 348, p. 453-458, out-dez. 2012.

MA, Y.; YAN, C.; ALSHAMERI, A.; QIU, X.; ZHOU, C.; LI, D. Synthesis and characterization of 13X zeolite from low-grade natural kaolin. Adv. Powder Technol., v. 25, n. 2, p. 495-499, mar. 2014.

MELO, C. R.; RIELLA, H. G. Síntese de zeólita tipo NaA a partir de caulim para obtenção de zeólita 5A através de troca iônica. Cerâmica, v. 56, n. 340, p. 340-346, out-dez. 2010.

MGBEMENA, C. O.; IBEKWE, N. O.; SUKUMAR, R.; MENON, A. R. R. Characterization of kaolin intercalates of oleochemicals derived from rubber seed (Hevea brasiliensis) and tea seed (Camelia sinensis) oils. J. King Saud Univ. Sci., v. 25, n. 2, p. 149-155, abr. 2013. 
MORAES, E. P.; MACHADO, N. R. C. F.; PERGHER, S. B. C. Síntese da zeólita a partir de um caulim brasileiro termicamente ativado. Acta Sci. Technol., v. 25, n. 1, p. 63-69, 2003.

MORAES, C. G.; RODRIGUES, E. C.; ANGÉLICA, R. S.; MACÊDO, E. N.; NEVES, R. F. Produção de zeólita analcima a partir de caulim amazônico. Cerâmica, v. 59, n. 352, p. 563-569, out-dez. 2013.

MOREIRA, J. C. Síntese e caracterização da zeólita 5A por troca iônica a partir de um resíduo da indústria de papel. 2013. Dissertação de Mestrado. Programa de Pós-Graduação em Engenharia Química, Universidade Federal de Santa Catarina - UFSC. 57p.

PINHEIRO, M. H. T.; LEMOS, V. P.; DANTAS, K. G. F.; VALENTIM, T. L. Especiação e quimiossorção de $\mathrm{Pb}$ (II) em rejeito de caulim. Quím. Nova, v. 36, n. 2, p. 272-278, 2013.

RIOS, C. A.; WILliAMS, C. D.; MAPLE, M. J. Synthesis of zeólitas and zeothypes by hydrothermal transformation of kaolinite and metakaolinite. Bistua, v. 5, n. 1, p. 15-26, 2007.

RODRIGUES, E. C.; MORAES, C. G.; FARIAS, B. M.; ROCHA Jr., C. A. F.; MACÊDO, E. N.; SOUZA, J. A.S. Síntese de zeólita A: estudo da variação de sódio e tempo de síntese. In: XIX Congresso Brasileiro de Engenharia Química - COBEQ. set. 2012.

SANTANA, D. L.; SARAIVA, A. C. F.; NEVES, R. F.; SILVA, D. L. Zeólita A sintetizada a partir de rejeitos do processo de beneficiamento do caulim. Cerâmica, v. 58, n. 346, p. 238-243, abr-jun. 2012. 